\title{
BMJ Open Quality Directed intervention to improve the rate of admission medication reconciliation in an acute care hospital
}

\author{
Htay Htay Kyi (D) , Saira Sundus, Huda Marcus, Jason Sotzen, Parker Suit, \\ James Cranford, Ghassan Bachuwa, Philip J McDonald
}

To cite: Kyi HH, Sundus S Marcus $\mathrm{H}$, et al. Directed intervention to improve the rate of admission medication reconciliation in an acute care hospital. BMJ Open Quality 2019;8:e000784. doi:10.1136/ bmjoq-2019-000784

Received 26 July 2019 Revised 10 December 2019 Accepted 18 December 2019

Check for updates

C Author(s) (or their employer(s)) 2019. Re-use permitted under CC BY-NC. No commercial re-use. See rights and permissions. Published by BMJ.

Department of Internal Medicine, Hurley Medical Center/Michigan State University, Flint, Michigan, USA

Correspondence to

Dr Philip J McDonald; pmcdona2@hurleymc.com

\section{ABSTRACT}

Introduction Electronic medication reconciliation systems are known to reduce medication errors. We hypothesised that refinement of the electronic medical record (EMR) and provider education could improve adherence to completion of admission medication reconciliation, thereby potentially limiting prescribing errors. Our goal was to improve the percentage of patients with medication reconciliation completed within 24 hours of admission to at least $90 \%$. Methods A prospective interventional study was conducted at a university-affiliated community hospital between 1 January 2017 and 30 September 2018. We determined the baseline percentage of medication reconciliations performed within 24 hours of admission, and those completed at any time prior to discharge from the hospital. Three plan-do-study-act cycles were then performed, with interventions including live and email reminders to complete medication reconciliation and addition of a column to EMR patient lists indicating whether reconciliation had been completed.

Results The percentage of medication reconciliations completed within 24 hours of admission was lowest for the pre-intervention cycle $(62.4 \%)$ and was highest for Cycle $3(80.9 \%)$. The percentage of reconciliations completed any time prior to discharge was higher and increased in a similar stepwise fashion from $71.1 \%$ to $88.4 \%$ through Cycle 3. There was a post-intervention trend toward a higher rate of reconciliation completion for patients aged 18-40. Male patients were also more likely to have their admission medication reconciliations completed prior to discharge.

Conclusion Our interventions resulted in a statistically significant $18.5 \%$ increase in the rate of admission reconciliation completion. Though this increase fell short of our goal, this study demonstrates that provider education and optimisation of the EMR can sustainably improve adherence with medication reconciliation, thereby fostering improved patient care. Further improvement could be achieved by focusing on the medication lists of our older patients and female patients.

\section{INTRODUCTION}

Prescribing errors result in approximately 1.5 million adverse drug events (ADEs) annually, at an added cost of more than $\$ 3$ billion due to associated morbidity and increased length of stay. ${ }^{12}$ Many of these errors are preventable and arise due to inaccurate medication history-taking, which occurs in up to $67 \%$ of hospitalisations. ${ }^{34}$ There are many barriers to obtaining an accurate medication history: patient age, literacy, language, visual and cognitive deficits, polypharmacy, lack of surrogate historians, provider fatigue, and lack of standardised medication lists across healthcare settings. ${ }^{15}$ When the medication list is inaccurate, reconciliation errors including medication omissions, duplications, dosing errors and inadvertent drug interactions can occur.

In response to this vital patient safety issue, the Joint Commission enacted a new National Patient Safety Goal in 2006 mandating that each accredited organisation implement a process for medication reconciliation at each transition of care, when medication errors are most likely to occur. ${ }^{6}{ }^{7}$ While the Joint Commission did not require the creation of a separate form for medication reconciliation, with the advent of electronic medical records (EMRs) most organisations have elected to implement electronic tools to support this process. These tools have been shown to significantly reduce both unintended medication discrepancies and non-intercepted ADEs. $^{7-9}$

Other healthcare organisations have successfully implemented various interventions to increase rates of medication reconciliation. Agrawal and $\mathrm{Wu}$ were able to improve compliance with the medication reconciliation process from 34\% to 98\%-100\% using electronic alerts. ${ }^{5}$ Taha et al achieved a $45 \%$ increase in compliance following implementation of an electronic reconciliation form. ${ }^{10}$ Automated email reminders sent to admitting residents by Johnson et al improved their medication reconciliation rate from $68 \%$ to $85 \% .^{11}$ Drawing on these and other authors' experiences, we performed directed intervention via refinement of our EMR and provider education to improve adherence to timely completion of admission medication 
reconciliation. Our goal was to improve the percentage of patients with medication reconciliation completed within 24 hours of admission from a baseline rate of $62.4 \%$ to at least $90 \%$.

\section{METHODS}

After obtaining Institutional Review Board (IRB) approval, we conducted a prospective interventional study at our 443-bed university-affiliated community hospital. All patients 18 years of age and older admitted to internal medicine resident teaching services between 1 January 2017 and 9 September 2018 were included. Patients admitted to private attending physicians were excluded; this heterogeneous population was not used as a control. Medication reconciliation was performed by resident physicians. A total of 8520 encounters from the hospital's EMR (Epic, Epic Systems Corporation) were analysed using SAS (SAS Institute Inc.) software. A baseline analysis was performed on pre-intervention data (from 1 January 2017 to 31 January 2018) to determine the percentage of medication reconciliations performed within 24 hours of admission, and those completed at any time prior to discharge from the hospital.

The study involved three sequential plan-do-study-act (PDSA) cycles (Cycle 1: 1 February 2018-23 April 2018; Cycle 2: 24 April 2018-30 June 2018; Cycle 3: 31 July 2018-30 September 2018), with the following interventions implemented at the start of each cycle:

Cycle 1: Live reminders to complete admission medication reconciliation delivered at daily noon conference lectures, and via email.

Cycle 2: The earlier interventions plus (1) a column was added to patient lists in the medical record to indicate whether the admission medication reconciliation had been completed and (2) random review of inpatient teams, with reminders based on deficiencies.

Cycle 3: The earlier interventions plus reminders by case managers who perform rounds with the medical teams, as well as peer-to-peer reminders to attending physicians.

From the cumulative patient data, we calculated the age distribution, the distribution of male versus female patients, the average length of stay, the percentage of patients for whom admission medication reconciliation was performed within 24 hours of admission and the percentage of patients for whom admission medication reconciliation was performed at any time prior to discharge. The rate of admission medication reconciliation completion within 24 hours of admission was then calculated for the pre-intervention cycle and each of the three PDSA cycles. The rate of admission medication reconciliation completion at any time prior to discharge was calculated for each of these time frames as well. The effect of the intervention was compared across age groups, stratified as 18-40 years, 41-60 years, or greater than 60 years old. Finally, the rates of admission medication reconciliation for male patients versus female patients were compared. $\mathrm{P}$ values were obtained for all major and subgroup analyses by performing a Pearson's $\chi^{2}$ test, and results were considered statistically significant for a $\mathrm{p}$ value of $<0.05$.

\section{RESULTS}

Demographic characteristics of the sample are reported in table 1 . The total sample size was 8520 . Mean age was $52,56 \%$ of patients were female and mean length of stay was 5.5 days. The percentage of admission medication reconciliations completed within 24 hours of admission was $69 \%$, and at any time prior to discharge was $77.9 \%$.

As shown in table 2, the percentage of admission medication reconciliations completed within 24 hours of admission was lowest for the pre-intervention cycle $(62.4 \%)$, followed by Cycle $1(76.7 \%)$ and Cycle $2(77.3 \%)$, and was highest for Cycle $3(80.9 \%)$, and this association was statistically significant, $\chi^{2}(3)=254.0, p<0.001$. Results from logistic regression analysis showed that the odds of medication reconciliations completion within 24 hours of admission were statistically significantly higher for Cycle 1 compared with the pre-intervention cycle $(\mathrm{OR}=2.0$, $95 \% \mathrm{CI}=1.7$ to 2.3$)$, Cycle 2 compared with the preintervention cycle $(\mathrm{OR}=2.1,95 \% \mathrm{CI}=1.8$ to 2.4$)$ and Cycle 3 compared with the pre-intervention cycle $(\mathrm{OR}=2.5$, $95 \% \mathrm{CI}=2.2$ to 3.0$)$. Although the increase in medication reconciliations completed within 24 hours of admission from Cycle 1 to Cycle 2 was not statistically significant, results showed that the odds of medical reconciliation completion were statistically significantly higher in Cycle 3 compared with Cycle $1(\mathrm{OR}=1.3,95 \% \mathrm{CI}=1.1$ to 1.6$)$ and in Cycle 3 compared with Cycle $2(\mathrm{OR}=1.2,95 \% \mathrm{CI}=1.01$ to 1.5$)$. The rate of medication reconciliation within 24 hours of admission improved by $14.3 \%, 14.9 \%$ and $18.5 \%$ from the pre-intervention cycle to Cycles 1, 2 and 3 , respectively.

The results in table 2 also show that the percentage of admission medication reconciliations completed any time prior to discharge was higher and increased in a similar stepwise fashion from the pre-intervention cycle $(71.1 \%)$ to Cycle $3(88.4 \%), \chi^{2}(3)=329.0, p<0.001$. Results from logistic regression analysis showed that the odds of medication reconciliation completion prior to discharge were statistically significantly higher for Cycle 1 compared with the pre-intervention cycle $(\mathrm{OR}=2.9,95 \% \mathrm{CI}=2.4$ to 3.4 ), Cycle 2 compared with the pre-intervention cycle $(\mathrm{OR}=2.7,95 \% \mathrm{CI}=2.2$ to 3.2$)$, and Cycle 3 compared with the pre-intervention cycle $(\mathrm{OR}=3.1,95 \% \mathrm{CI}=2.6$ to 2.7$)$. However, the differences in medication reconciliation completion at any time prior to discharge between Cycles 1,2 , and 3 were statistically nonsignificant.

The effect of intervention was statistically significant and similar in magnitude for all age groups, though there was a post-intervention trend toward a higher rate of admission reconciliation for patients aged 18-40 within 24 hours of admission (85.2\%) and at any time prior to discharge (89.2\%) compared with that of older patients 
Table 1 Demographics and descriptive data $(n=8520)$

\begin{tabular}{|c|c|}
\hline Age, mean (SD) & $52.0(18.8)$ \\
\hline \multicolumn{2}{|l|}{ Gender } \\
\hline Female, n (\%) & $4851(56.9)$ \\
\hline Male, n (\%) & $3669(43.1)$ \\
\hline Length of stay, days (SD) & $5.5(6.6)$ \\
\hline $\begin{array}{l}\text { Admission medication reconciliation completed } \\
\text { within } 24 \text { hours of admission, } n(\%)\end{array}$ & $5878(69.0)$ \\
\hline $18-40$ years $(n=2550), \%$ & 70.7 \\
\hline $41-60$ years $(n=3022), \%$ & 68.7 \\
\hline$>60$ years $(n=2948), \%$ & 67.8 \\
\hline $\begin{array}{l}\text { Admission medication reconciliation completed } \\
\text { at any time prior to discharge, } \mathrm{n}(\%)\end{array}$ & $6639(77.9)$ \\
\hline $18-40$ years, \% & 76.0 \\
\hline $41-60$ years, $\%$ & 79.5 \\
\hline$>60$ years, $\%$ & 78.1 \\
\hline \multicolumn{2}{|l|}{ Primary diagnosis } \\
\hline Obstetric/gynecologic conditions & $10.4 \%$ \\
\hline Pulmonary conditions (eg, asthma, COPD) & $8.9 \%$ \\
\hline Drug toxicity or dependence & $7.7 \%$ \\
\hline Gastrointestinal conditions & $6.6 \%$ \\
\hline Other bacterial infections & $4.9 \%$ \\
\hline Heart failure & $4.6 \%$ \\
\hline Sepsis & $4.5 \%$ \\
\hline Diabetes & $4.3 \%$ \\
\hline Other neurologic conditions & $4.2 \%$ \\
\hline Acute renal failure & $4.0 \%$ \\
\hline Vascular conditions including thrombosis & $3.5 \%$ \\
\hline Acute coronary syndrome & $3.5 \%$ \\
\hline Pneumonia & $2.9 \%$ \\
\hline Other cardiac conditions & $2.8 \%$ \\
\hline Arrhythmias & $2.6 \%$ \\
\hline Other conditions & $2.6 \%$ \\
\hline Stroke and intracranial haemorrhage & $2.5 \%$ \\
\hline Elective surgery and associated complications & $2.3 \%$ \\
\hline Orthopaedic conditions & $2.2 \%$ \\
\hline Urinary tract infection & $2.1 \%$ \\
\hline Psychiatric conditions & $2.0 \%$ \\
\hline Malignancy & $2.0 \%$ \\
\hline Seizure & $1.8 \%$ \\
\hline Endocrine & $1.7 \%$ \\
\hline Viral disease & $1.4 \%$ \\
\hline Sickle cell disease & $1.4 \%$ \\
\hline Abdominal infections & $1.0 \%$ \\
\hline Urologic conditions & $0.9 \%$ \\
\hline Trauma and wounds & $0.7 \%$ \\
\hline
\end{tabular}

COPD, chronic obstructive pulmonary disease. (see table 2). A higher percentage of male patients $(80.3 \%)$ had their admission medication reconciliation completed prior to discharge than did female patients $(76.1 \%)(\mathrm{p}<0.001)$.

\section{DISCUSSION}

Our study demonstrates that simple, tiered interventions can produce significant increases in provider adherence to completing admission medication reconciliation. Other groups have typically implemented one or a few interventions to achieve the same goal, with variable success. ${ }^{5} 1011$ We utilised a multidisciplinary approach which included in-person and electronic reminders, more akin to the transition of care team established by Kreckman et al. ${ }^{7}$ Following Cycle 1, it became evident from discussions with resident physicians that not all of them were aware of our initiative since, due to their busy schedules, they had missed noon conferences or had not yet read our emails. Therefore, in addition to resending these reminders and speaking at additional conferences we modified the EMR in a novel way for Cycle 2, adding a column to the medicine teams' patient lists indicating whether the admission reconciliation had been completed for each patient. The column itself served as a constant reminder to providers to complete the reconciliation and allowed for rapid review and targeted reminders by the investigators and attending physicians for residents to correct any deficiencies. Case managers were employed to provide further reminders to providers during Cycle 3 , since these individuals more frequently review patient lists during the course of their non-clinical duties. Peerto-peer reminders by the faculty advisor for this project to other attending physicians were also included during Cycle 3 to encourage additional buy-in among the medicine teams. It was discovered during this cycle that some providers had misunderstood the goal of the project and believed they would be penalised for not meeting a quality metric; this was corrected through further education.

The percentage of admission medication reconciliations completed within 24 hours of admission increased in a stepwise fashion from the pre-intervention cycle through Cycle 3. Our interventions resulted in an $18.5 \%$ improvement in this metric. The percentage of reconciliations completed at any time prior to discharge increased similarly to $88.4 \%$, but did not quite reach our goal of $90 \%$ adherence. These results indicate that there is significant room for improvement in the timeliness of admission medication reconciliation at our institution. Johnson et al utilised automated email reminders to this end, though the reminders were sent after 24 hours had elapsed since admission. ${ }^{11}$ It may be useful to employ similar alerts, but to move them up to ensure that reconciliation is completed before 24 hours elapse.

The trend towards a higher rate of medication reconciliation for younger patients likely reflects the fact that younger patients tend to take fewer medications, making reconciliation faster and easier for providers. Similarly, 
Table 2 Intervention effects on admission medication reconciliation

\begin{tabular}{|c|c|c|c|c|}
\hline & $\begin{array}{l}\text { Pre-Intervention, } \\
\text { n (\%) }\end{array}$ & Cycle 1,n (\%) & Cycle 2, n (\%) & Cycle 3,n (\%) \\
\hline $\begin{array}{l}\text { Admission medication reconciliation completed within } \\
24 \text { hours of admission }\end{array}$ & $3125(62.4)$ & 942 (76.7) & 775 (77.3) & 1037 (80.9) \\
\hline $18-40$ years & 944 (61.2) & 302 (86.5) & 218 (83.8) & 339 (85.2) \\
\hline Female & 667 (60.9) & 209 (88.9) & 149 (85.6) & 237 (86.8) \\
\hline Male & 277 (62.0) & 93 (81.6) & 69 (80.2) & $102(81.6)$ \\
\hline Female & $531(61.3)$ & $124(67.0)$ & $134(74.9)$ & $162(76.4)$ \\
\hline Male & $569(64.8)$ & 213 (78.9) & $146(78.9)$ & $197(79.4)$ \\
\hline$>60$ years & $1081(62.8)$ & 303 (71.5) & 277 (73.3) & $339(80.0)$ \\
\hline Female & $600(62.0)$ & 167 (73.9) & 162 (75.3) & $176(79.3)$ \\
\hline Female & $713(65.1)$ & 222 (94.5) & $160(92.0)$ & $246(90.1)$ \\
\hline Male & 309 (69.1) & 101 (88.6) & 77 (89.5) & 109 (87.2) \\
\hline $41-60$ years & 1288 (73.8) & 397 (87.3) & $306(84.1)$ & 411 (89.3) \\
\hline Female & $620(71.6)$ & 152 (82.2) & $148(82.7)$ & 187 (88.2) \\
\hline Male & 668 (76.1) & $245(90.7)$ & $158(85.4)$ & 224 (90.3) \\
\hline$>60$ years & 1252 (72.7) & $356(84.0)$ & 326 (86.2) & 367 (86.6) \\
\hline Female & 686 (70.9) & $191(84.5)$ & 179 (83.3) & $189(85.1)$ \\
\hline Male & $566(75.1)$ & 165 (83.3) & $147(90.2)$ & $178(88.1)$ \\
\hline
\end{tabular}

we showed that male patients were statistically significantly more likely to have their admission reconciliations completed than did female patients; female gender is a risk factor for polypharmacy. ${ }^{12}$ While providers should always take the time to perform an accurate medication history and reconciliation, in order to prevent potentially dangerous and costly errors, our results suggest that increased effort should be dedicated to older patients and to female patients.

Meta-analysis has shown that electronic medication reconciliation tools save time and reduce provider workload. ${ }^{9}$ Utilisation of 'side-by-side' medication lists and 'hard stops' have the potential to further increase adherence with this process; however software alone is unable to prevent prescribing errors. ${ }^{58}$ We agree with Kreckman et al that medication reconciliation should be viewed as a continuous process rather than a series of steps (admission, transfer, discharge). ${ }^{7}$ Each healthcare organisation is responsible for creating a 'culture of accountability' with regard to accurate and timely medication reconciliation. ${ }^{1}$

Others have previously shown that similar interventions are readily sustainable contingent on strong collaboration with all members of the healthcare team including nurses, pharmacists and case managers. ${ }^{10}$ In order to determine if our interventions were also sustainable, we examined the percentage of patients with admission medication reconciliations completed within 24 hours of admission and those completed at any time prior to discharge for the period from 1 October 2018 to 31 March 2019. There was a small but statistically nonsignificant decrease in the former from the third PDSA cycle $(88.4 \%)$ to the postintervention period $(86.9 \%), \chi^{2}(1)=1.7, p=0.18$. The latter showed a small, statistically significant decrease from $80.9 \%$ to $77.5 \%, \chi^{2}(1)=5.9, p=0.02$. These data suggest that ongoing reminders are needed to sustain high rates of timely admission medication reconciliation at our facility.

This study's main strength was the large sample size. Use of a robust EMR allowed for rapid data polling and analysis which, in turn, facilitated the framing and implementation of subsequent PDSA cycles. There were several limitations to our study. First, the single centre design likely limits generalisability since other institutions utilise different EMRs, may not have as many support staff and have differently structured internal medicine teaching services. Second, like other investigators, we assessed adherence to the process of medication reconciliation but did not count patients' medications or examine the accuracy of individual reconciliations for medication discrepancies. ${ }^{11}$ Third, we cannot conclude which aspect of our interventions (eg, provider education or implementation of a new EMR column) was most effective. Learning effect may have played a role in improving the rate of admission medication through progressive cycles; 
however the attrition observed in the post-intervention period argues against this.

\section{CONCLUSION}

Medication reconciliation is proven to reduce prescribing errors and is therefore an integral part of patient safety. The interventions we implemented resulted in a statistically significant $18.5 \%$ increase in the rate of admission reconciliation completion at our institution. Though this increase fell short of our goal, this project demonstrates that provider education and optimisation of the EMR can readily improve adherence with medication reconciliation, thereby fostering improved patient care. Our results also suggest that further improvement could be achieved by paying closer attention to the medication lists of our older patients and female patients.

Acknowledgements The authors thank Michael Hicks, MD (Department of Radiology, University of Michigan) for his valuable help with our project.

Contributors HHK, SS and HM formulated the study protocol and supervised the interventions. JC performed the statistical analysis and assisted with interpretation. HHK, SS, HM, JS and PS reviewed the study findings and prepared the manuscript. PJM and GB served as scientific advisors and reviewed the manuscript.

Funding The authors have not declared a specific grant for this research from any funding agency in the public, commercial or not-for-profit sectors.

Competing interests None declared.

Patient consent for publication Not required.

Provenance and peer review Not commissioned; externally peer reviewed. Data availability statement All data relevant to the study are included in the article.

Open access This is an open access article distributed in accordance with the Creative Commons Attribution Non Commercial (CC BY-NC 4.0) license, which permits others to distribute, remix, adapt, build upon this work non-commercially, and license their derivative works on different terms, provided the original work is properly cited, appropriate credit is given, any changes made indicated, and the use is non-commercial. See: http://creativecommons.org/licenses/by-nc/4.0/.

\section{ORCID iDs}

Htay Htay Kyi http://orcid.org/0000-0001-6031-5192

Philip J McDonald http://orcid.org/0000-0001-6369-5506

\section{REFERENCES}

1 Steeb D, Webster L, American Pharmacists Association, et al. Improving care transitions: optimizing medication reconciliation. $J$ Am Pharm Assoc 2012;52:e43-52.

2 Bates DW, Spell N, Cullen DJ, et al. The costs of adverse drug events in hospitalized patients. adverse drug events prevention Study Group. JAMA 1997;277:307-11.

3 Tam VC. Frequency, type and clinical importance of medication history errors at admission to hospital: a systematic review. Can Med Assoc J 2005;173:510-5.

4 Rothschild JM, Federico FA, Gandhi TK, et al. Analysis of medication-related malpractice claims: causes, preventability, and costs. Arch Intern Med 2002;162:2414-20.

5 Agrawal A, Wu WY. Reducing medication errors and improving systems reliability using an electronic medication reconciliation system. Jt Comm J Qual Patient Saf 2009;35:106-14.

6 The Joint Commission. Using medication reconciliation to prevent errors. Sentinel event alert 2006;35:1-4.

7 Kreckman J, Wasey W, Wise S, et al. Improving medication reconciliation at hospital admission, discharge and ambulatory care through a transition of care team. BMJ Open Qual 2018;7:e000281.

8 Hron JD, Manzi S, Dionne R, et al. Electronic medication reconciliation and medication errors. Int J Qual Health Care 2015;27:314-9.

9 Wang $\mathrm{H}$, Meng L, Song J, et al. Electronic medication reconciliation in hospitals: a systematic review and meta-analysis. European Journal of Hospital Pharmacy 2018;25:245-50.

10 Taha $\mathrm{H}$, Abdulhay D, Luqman N, et al. Improving admission medication reconciliation compliance using the electronic tool in admitted medical patients. BMJ Qual Improv Rep 2016;5:u209593. w4322.

11 Johnson K, Burkett GS, Nelson D, et al. Automated e-mail reminders linked to electronic health records to improve medication reconciliation on admission. Pediatr Qual Saf 2018;3:e109.

12 Feng X, Tan X, Riley B, et al. Prevalence and geographic variations of polypharmacy among West Virginia Medicaid beneficiaries. Ann Pharmacother 2017;51:981-9. 